\title{
Desconstrução e design gráfico: a redesconstrução visual da cultura
}

Deconstruction and graphic design: the visual redeconstruction of culture

BECCARI, Marcos N.; Doutor; Universidade Federal do Paraná

contato@marcosbeccari.com

\section{Resumo}

Este ensaio apresenta um breve panorama conceitual acerca da relação entre desconstrução e design gráfico, no intuito de indicar como a cultura se desvela enquanto redesconstrução visual. Utilizando como referências principais Jacques Derrida, Ellen Lupton e Abbott Miller, começo apresentando a pauta em questão e delineio, como pano de fundo, a tradição moderno-formalista no design gráfico. Em seguida, descrevo como a desconstrução foi uma noção chave para a crítica pós-moderna e finalizo apontando o papel atual da desconstrução visual na cultura.

Palavras Chave: Desconstrução, Design Gráfico, Design e Cultura.

\begin{abstract}
This essay presents a brief conceptual overview about the relationship between deconstruction and graphic design, in order to indicate how the culture reveals itself as a visual redeconstruction. Using as main references Jacques Derrida, Ellen Lupton and Abbott Miller, I begin by presenting the question and I outline, as a background, the modern-formalist tradition in graphic design. Then I describe how deconstruction was a key notion for the postmodern criticism and I end by pointing out the role of visual deconstruction in culture.
\end{abstract}

Keywords: Deconstruction, Graphic Design, Design and Culture. 


\section{Introdução}

[...] hoje, o único modernismo digno desse nome é o modernismo antimoderno. (KUNDERA, 2006, p. 56).

O termo "desconstrução" costuma servir para descrever qualquer discurso que favoreça a complexidade em detrimento da simplicidade. Algo que faça alusão ao olhar crítico, ao ato de questionar. Jacques Derrida (2008) introduziu o conceito no livro De la grammatologie (Gramatologia), publicado na França em 1967.

A partir de então, a desconstrução tornou-se parte de um campo crítico mais amplo conhecido como "pós-estruturalismo", associado a nomes como Roland Barthes e Michel Foucault. Entre muitos artistas e designers que se formaram nas décadas de 1970 e 1980, já era consideravelmente disseminada a ideia geral de que as formas culturais "fabricam" categorias supostamente neutras ou naturais como raça, sexualidade, classe e valor estético.

Nos Estados Unidos, a interseç̧ão entre pós-estruturalismo e design gráfico foi amplamente explorada na Cranbrook Academy of Art, sob a liderança de Katherine McCoy (1990). A importância histórica e teórica do que ali foi desenvolvido é salientada em Design escrita pesquisa, onde Ellen Lupton e Abbott Miller (2011, p. 8) esclarecem que a desconstrução "é uma postura, não um estilo". Em Cranbrook, essa postura balizava experimentos que brincavam com as convenções da leitura, no intuito de traduzir visualmente a crítica do pós-estruturalismo aos "significados fixos". Não tardou, todavia, para que a desconstrução fosse criticada como, nos termos de Michael Collins e Andreas Papadakis (1989), um clichê antimoderno que meramente catalisava tendências diversas que já existiam nos campos do design, da arquitetura, da moda etc.

Neste artigo, esboço um breve e introdutório panorama conceitual acerca da relação entre desconstrução e design gráfico, com o objetivo de sinalizar como a noção de "cultura" se desvela, sob o prisma pós-estruturalista do design gráfico, enquanto construção e desconstrução visual. Para contextualizar a relação em questão, cabe-me acenar determinado viés acerca da história do design gráfico. Qual seja, sou desfavorável tanto a uma "história de estilos" quanto a um cânone de movimentos que se sucedem, mas concordo com a asserção de Lupton e Miller (2011, p. 62) segundo a qual, "Em nossa profissão, assim como na arquitetura e nas belas artes, o movimento na direção de uma maior consciência histórica está ligado a uma revisão do modernismo". No âmbito da reflexão aqui proposta, parece-me suficiente revisar o modernismo na esteira de um formalismo do design gráfico.

\section{O formalismo no design gráfico}

O que se costuma chamar de design moderno é o movimento que nasce em resposta à Revolução Industrial, quando artistas, arquitetos e artesãos reformadores buscaram conferir um discurso crítico à fabricação de objetos. Segundo Lupton e Miller, (2011, p. 158), "Criar uma distância entre o design e a vida cotidiana foi um dos atos fundadores do modernismo, que estabeleceu uma divisória entre a cultura de consumo e a vanguarda crítica". William Morris, por 
exemplo, deu início ao ideal do designer como crítico, aspirando ir além do que as pessoas já desejam para "ensiná-las" a desejar algo melhor (WATKINSON, 1990).

Analogamente, o design gráfico enquanto disciplina pode ser contextualizado a partir dos movimentos de arte moderna e de vanguarda no início do século XX (como o Construtivismo, o De Stijl e a própria Bauhaus), os quais, como se sabe, posicionavam-se fora ou "acima" das multidões irrefletidas, no intuito de transmitir visões alternativas sobre a cultura que as circunscreve ${ }^{1}$. Nesse contexto, uma parte significativa das concepções teóricas do design se amparava em "teorias da percepção" que concebiam a visão como faculdade imutável, comum a todos os indivíduos de todas as épocas.

Essas teorias da percepção demarcam uma tendência que pode ser suscintamente descrita como formalismo no design gráfico. Formalismo designa a ênfase da forma sobre o conteúdo ou significado. No campo da crítica de arte, trata-se da visada segundo a qual tudo o que é necessário para explicar uma obra está contido em sua composição visual. O contexto da obra, o motivo representado, o pano de fundo sociocultural e a vida do artista, nada disso importa mais do que as categorias formais empregadas ${ }^{2}$.

Do princípio fundamental de que existem padrões formais comuns às obras de arte ligadas a diferentes períodos/movimentos derivaram novas abordagens, cuja lógica envolvia associar um padrão formal a um contexto cultural ou de qualquer outro tipo (étnico, social, geográfico e assim por diante) $)^{3}$. Na passagem para o século $X X$, esses estudos, dentre outros, deram origem ao célebre Círculo de Viena, que, na contramão da corrente positivista de sua época, desvinculou a história da arte da noção de uma evolução tecnológica ou funcional, passando a escrever uma história da percepção humana, feita de retomadas e deslocamentos entre padrões de comunicação e visibilidade.

Como membro do Círculo de Viena, o filósofo e sociólogo Otto Neurath elaborou, na década de 1920, o Isotype (Sistema Internacional de Educação Tipográfica Pictórica), um modelo de como representar informações complexas por meio de unidades pictóricas elementares (NEURATH, 2010). O objetivo de Neurath era unir duas tradições opostas: o racionalismo, que estuda a realidade através da lógica, e o empirismo, segundo o qual a observação é a chave para o conhecimento. Seu esforço, então, foi o de combinar visualmente realismo empírico e abstração lógica, tomando a síntese formal como um antídoto para a escrita, a ilustração e outros meios "datados" de comunicação.

O legado de Neurath abriu espaço à concepção moderna de linguagem visual, tema que permanece caro ao design gráfico. Quanto a isso, Lupton e Miller (2011) elencam três obras emblemáticas: Language of Vision (1944) de Gyorgy Kepes, Art and Visual Perception (1954) de Rudolph Arnheim, e A Primer of Visual Literacy (1973) de Donis Dondis. O denominador comum é a base teórica da Gestalt, teoria segundo a qual o "todo formal" existe independentemente de

\footnotetext{
${ }^{1}$ Segundo Artur Freitas (2007, p. 21), a arte de vanguarda "[...] foi a panaceia da própria ideia de autonomia - uma espécie de apelo genérico, utópico e contraditório à capacidade de intervenção da arte sobre o real".

2 O formalismo moderno está intimamente ligado à escola da "visibilidade pura", conhecida por elaborar, no final do século XIX (ex. Alois Riegl, entre outros), mas também no século XX (ex. Clément Greenberg), grandes esquemas formais para explicar as obras de arte. Cf. BARROS, 2012.

${ }^{3}$ Wilhelm Worringer, por exemplo, identificou nas sociedades mediterrâneas clássicas uma tendência à assimilação literal do ambiente, ao passo que as sociedades nórdicas teriam favorecido modelos de representação mais abstratos. Cf. WORRINGER, 2014.
} 
suas partes, de modo a atribuir à percepção uma faculdade unificadora intrínseca. Essa ideia de que o design é, no fundo, uma atividade formal abstrata já alicerçava o Curso Básico que Johannes Itten iniciou na Bauhaus em 1919, que influenciou os cursos de Kandinsky e Moholy-Nagy na mesma instituição, sendo posteriormente retomado por Kepes na New Bauhaus, em Chicago.

A tradição formalista do design gráfico, em suma, foca-se no modo como um significado, um valor e uma função podem ser transmitidos por meio de regras formais perenes. Tais regras sugerem uma cultura unificada e racional, na qual os signos parecem ser marcas naturais das ideias ou essências - algo como uma caverna de Platão reconstruída em um laboratório modernista ${ }^{4}$.

Claro que, no entanto, o formalismo é apenas uma faceta mínima do modernismo, cuja abrangência cultural é irredutível a um único aspecto. No caso da literatura moderna, por exemplo, Milan Kundera (2006) descreve duas acepções distintas: na França, o moderno era antirracionalista e antinaturalista, ao passo que na Europa Central o moderno se opunha à tradição romântica. No caso do design moderno, Daniel Portugal (2017) identifica em figuras como William Morris e Victor Papanek a ressonância de valores ao mesmo tempo iluministas e românticos, ou seja, de duas tradições modernas que sempre estiveram em disputa.

Mas, ainda no registro moderno-formalista, é pertinente mencionar um estudo do antropólogo Alexander Luria, comentado por Walter Ong (1982, p. 49-52), acerca da percepção de formas abstratas. Nesse estudo, os habitantes de um vilarejo remoto da Rússia foram convidados a interpretar figuras geométricas elementares: círculo, quadrado e triângulo. Alguns aldeãos sabiam ler e escrever, outros não. Enquanto os alfabetizados identificaram as figuras pelo nome, os analfabetos as associaram com objetos de seus ambientes cotidianos: o círculo podia ser um balde, o quadrado, um banco, o triângulo, um telhado. Essa breve pesquisa de Luria indica que a capacidade de abstração, ou seja, de dissociar as formas de um contexto de comunicação figurativa, é uma habilidade sofisticada e não uma faculdade universal. Ela requer a racionalidade própria de uma cultura letrada, fora da qual nenhuma tradição formalista seria concebível.

\section{Desconstrução e design gráfico}

À medida que o modernismo se tornava canônico nos cursos de design das décadas de 1950 e 1960, seus críticos se proliferavam, delineando o discurso do design pós-moderno que ganhava força na Itália e nos Estados Unidos. No caso da Cranbrook Academy of Art, como relata McCoy (1990), o livro Learning from Las Vegas, de 1972, tornou-se uma porta de entrada, dentre outras $^{5}$, para o pós-estruturalismo: os arquitetos Robert Venturi, Denise Scott e Steven Izenour (2003) encaravam Las Vegas como um espécime etnográfico, uma autêntica amostra da vida popular que tende a ser menosprezada pela sabedoria modernista.

A ironia dos autores se explicita ao elegerem uma loja de ovos em forma de pato (o famoso

\footnotetext{
${ }^{4}$ Analogia cunhada por Leo Steinberg e salientada por Rosalind Krauss, que elaboraram as críticas mais severas contra o formalismo artístico. Cf. STEINBERG, 2008, p. 79-125; CARRIER, 2002, p. 71-85.

${ }^{5} \mathrm{~A}$ autora menciona vários outros livros que ajudaram a popularizar o pós-estruturalismo nos Estados Unidos, dentre os quais Mythologies, de Roland Barthes (publicado em 1972), e The Anti-Aesthetic: Essays on Postmodern Culture, de Hal Foster (publicado em 1983).
} 
"pato de Long Island") como ícone da arquitetura moderna: forma e função colidem em harmonia na edificação monolítica (Fig. 1). Em contrapartida, os restaurantes típicos de beira da estrada, que nos Estados Unidos se assemelham a uma caixa chata atravessada por uma placa gigante, são apresentados pelos autores como artefatos culturalmente espontâneos, dissociados do mundo estético do design e da arquitetura.

Figura 1 - O pato de Long Island

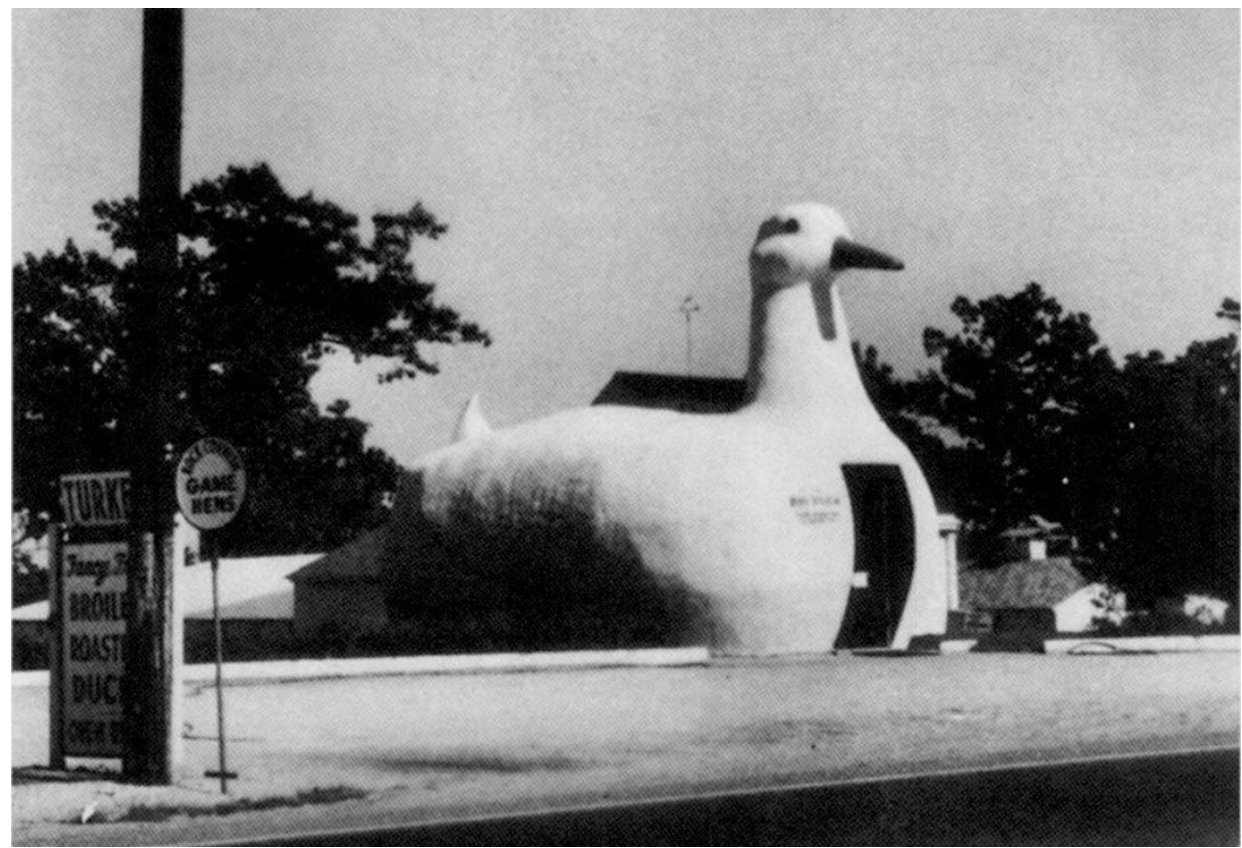

Fonte: VENTURI; SCOTT-BROWN; IZENOUR, 2003, p. 114.

Antes de avançar nas consequências desse novo olhar, cumpre traçar um recuo conciso sobre a teoria da desconstrução. A dissecação da arte e da filosofia ocidentais levada a cabo por Jacques Derrida (2008) parte de sua leitura crítica do Curso Geral de Linguística de Ferdinand Saussure, texto fundamental para os campos da linguística estruturalista, da semiótica e da antropologia. Saussure afirmava que o sentido dos signos não se encontra nos próprios signos: não há uma ligação natural entre o significante (o aspecto material do signo) e o significado (seu referente). Em vez disso, o sentido de um signo se dá apenas por sua relação com os outros signos de um sistema. Se o signo é vazio fora da "estrutura" que o enquadra, a linguagem não é um veículo transparente para representar conceitos preexistentes. Para Saussure, enfim, um pensamento sequer existiria sem o corpo da linguagem.

Em Gramatologia, Derrida argumenta que, embora Saussure tenha contribuído para revelar o vazio dos valores no âmago da linguagem, ele se limitava a estudar a linguagem falada, encarando a escrita como mera simplificação representacional da fala. A crítica de Derrida (2008, p. 39) mira nessa noção de escrita como cópia secundária da fala, e afirma que "a escrita habita a fala", transformando sua gramática e som. Afinal, qual conceito ou som é representado na pontuação, em palavras em negrito ou itálico e nas diversas formas de espacejamento? Essas marcas não fonéticas são elementos essenciais da escrita, como lacunas negativas entre signos positivos. De acordo com Derrida (idem), o alfabeto aprendeu a confiar nesses "silenciosos servos gráficos" que, como a moldura de um quadro, parecem estar "fora" do conteúdo e da estrutura 
interna de uma obra e, contudo, são condições necessárias para sua criação e leitura. Lupton e Miller (2011, p. 14) concebem algo similar em relação à tipografia e ao design gráfico:

Espacejamento e pontuação, fronteiras e molduras: esses são os territórios da tipografia e do design gráfico, aquelas artes marginais que tornam legíveis os textos e as imagens. A substância da tipografia não está no alfabeto em si - as formas genéricas de caracteres e seus usos convencionados -, mas no contexto visual e nas formas gráficas específicas que materializam o sistema da escrita. O design e a tipografia trabalham nos limites da escrita, determinando a forma e o estilo das letras, os espaços entre elas, e sua localização na página.

Ainda na teoria de Derrida, a "desconstrução" é um modo de perguntar como as diferentes formas de representação habitam a realidade. Assim, em vez de tentar revelar o significado de algo por meio das regras formais que o representam (formalismo), trata-se de assumir que não há nada além de representações arbitrárias que se correspondem. A oposição entre os conceitos de natureza e cultura, por exemplo, só faz sentido enquanto binômio: a natureza depende da ideia de cultura para ser compreendida, ao mesmo tempo em que a cultura está embutida na natureza. 0 mesmo poderia ser dito em relação ao conceito judaico-cristão de corpo como invólucro exterior da alma interior, bem como às noções de original e cópia, forma e conteúdo, essência e aparência etc.

Tal correlação não é diferente, por certo, da que ocorre nas oposições entre moderno e pós-moderno, formalismo e desconstrução: categorias que, se isoladas, tornam-se vazias de sentido. Com isso em mente, podemos avançar nas consequências da incorporação da desconstrução por parte dos designers. A supracitada proposta de "aprender com Las Vegas" serviu não apenas como uma porta de entrada ao pós-estruturalismo, mas também para demarcar uma nova perspectiva crítica e distanciada, já que seus autores se dirigiam aos herdeiros tardios do modernismo, e não aos criadores anônimos das construções à beira das estradas - tanto é que o místico "pato de Long Island" passou a ser preservado como monumento histórico, um objeto cult da arquitetura.

De maneira análoga, os designers do Push Pin Studio, vanguarda nova-iorquina do design gráfico nas décadas de 1960 e 1970 (CHWAST, 2004), buscavam por vozes supostamente espontâneas e despretensiosas para confrontar o imaginário moderno: sinalização informal, clip art, mídia popular etc. Ou seja, a desconstrução motivava os designers a tratar a "baixa cultura" como matéria-prima original de um estilo inovador. No âmbito do ensino, como narram Lupton e Miller (2011, p. 161),

O vernacular comercial fez parte de um experimento tipicamente modernista da Cranbrook Academy a partir da década de 1970. Os alunos eram convidados a submeter um objeto tipográfico comum - como um anúncio das páginas amarelas ou um rótulo de ketchup - a uma série de operações formais, desde estudos racionais do grid até composições de forma livre. O exercício era uma lição prática para a descoberta da distância entre "nós" e "eles", entre os esotéricos experimentos de laboratório dos alunos de graduação e os espécimes que eles habilmente dissecavam. O que esses estudos pareciam negligenciar é o fato de que o "vernacular comercial", aparentemente naïve, muitas vezes pertencia a uma estratégia de marketing sofisticada. 
Ao encararem artefatos comerciais comuns como fontes a serem estudadas com admiração e distanciamento, esses estudantes não apenas retomaram e reescreveram os "hieróglifos" do cotidiano, como também buscaram se apropriar de um "outro" exótico, como conoisseurs de uma subclasse visual. A transformação do mundano em mágico, do baixo em alto, foi o tema da exposição High and Low: Modern Art and Popular Culture, realizada no MoMA em 1990. Segundo os curadores (GOPNIK, VARNEDOE, 1990), a proposta era mostrar como a "matéria bruta" da publicidade, das histórias em quadrinhos, do graffiti etc. foi transformada, durante a década de 1980, em combustível para um novo valor estético ${ }^{6}$. Ora, a necessidade de transformar o comum em algo novo, a busca por um espaço acima e para além da corrente dominante, a oposição da vanguarda às normas do bom gosto, essas são as características da visão modernista.

Segundo Robin Kinross (1994), o princípio da desconstrução veio a justificar em larga medida uma nova roupagem romântica para os velhos ideais de bom gosto e originalidade no design. Uma vez que o significado não está fixo nas formas de expressão, os designers se sentem como que "autorizados" a ressignificar as coisas, a criar novos sentidos, sendo o "bom design" aquele que investe na maior abertura interpretativa. Caso Kinross esteja certo, essa abordagem apresenta uma resposta um tanto controversa ao espírito pós-estruturalista. Na esteira da "morte do autor", por exemplo, tema caro a Barthes e a Foucault", o designer ou artista não é um livre forjador da linguagem, dos significados, das convenções e assim por diante; em vez disso, ele sempre obedece a uma grade limitada de possibilidades que esses códigos apresentam.

Em todo caso, a questão a ser por ora destacada é que a desconstrução visual parece ser indissociável da tradição moderno-formalista do design gráfico, do mesmo modo que a "baixa" mídia de massa e a "alta" arte de vanguarda, por exemplo, nunca habitaram mundos separados. Nos termos de Lupton e Miller (2011, p. 166), "O heroísmo da vanguarda repousa em sua visão do design como força social libertadora. Já a atual crise do modernismo repousa no contraditório desejo de ocupar um espaço fora da sociedade e simultaneamente transformá-la". Uma lição importante, todavia, a ser depreendida da desconstrução não é tanto que as categorias são vazias em si mesmas ou que os opostos se correspondem, mas principalmente que a cultura é como uma gramática que abarca a tudo, não sendo possível contemplá-la de um ponto de vista neutro ou externo. Sendo assim, em vez de insistir numa postura crítica a partir de uma posição superior e distanciada, o design também pode enxergar criticamente a cultura como um modo ativo de desconstrução, isto é, mostrando como os diversos valores e significados habitam a cultura enquanto visualidade.

\section{Redesconstruções: cultura e visualidade}

No seio da filosofia ocidental, a passagem da oralidade à escrita é marcada, como se sabe, pela filosofia de Platão. Mas, sendo uma novidade, a escrita provocava certa desconfiança, principalmente numa tradição oral como era aquela de Homero. O filósofo então optou por escrever sob a forma de diálogos, cuja expressão retórica poderia angariar maior adesão. Assim,

\footnotetext{
${ }^{6}$ No campo da arquitetura, uma proposta similar consiste na exposição Deconstructivist Architecture, realizada em 1988 também no MoMA. Cf. JOHNSON; WIGLEY, 1988.

${ }^{7}$ Ver, respectivamente: BARTHES, 2004, p. 57-64; FOUCAULT, 2011, p. 264-298.
} 
na maioria dos diálogos é Sócrates quem valida os pensamentos de Platão. Tecer uma sequência de indagações visando extrair de seu interlocutor alguma contradição que o faça repensar suas ideias, até chegar numa suposta verdade universal: eis o método socrático. Desse modo, tal como um profeta, Platão pregava silenciosamente não o céu dos deuses, mas um outro mais racional, aquele das ideias.

Sua manobra escrita, com efeito, consistia em desconstruir os mitos, ainda que por meio de outros, aqueles que fomentam a crítica e o questionamento do mundo. Antes de escrever, porém, Platão investiu numa forte campanha contra Demócrito, de quem queimou todos os pergaminhos que conseguiu recolher. Não sem motivo: a tese do sofista era a de que, grosso modo, a verdade não existe. $O$ que temos são as interpretações. $O$ homem é a medida de todas as coisas (máxima de Protágoras, discípulo de Demócrito) porque o homem é quem nomeia todas as coisas. Não havendo nenhum céu inteligível de onde tirar os significados puros, restava a visão de um único mundo feito de metáforas, designações e interpretações a serem continuamente reelaboradas, refutadas, aceitas ou transformadas - ou seja, o mundo da cultura humana (PAGOTTO-EUZEBIO, 2010).

A desconstrução parece ser parte integrante da cultural ocidental, tanto quanto a escrita denota a primazia da abstração nessa mesma cultura. No mundo dos objetos humanos, nada além dos textos ainda congrega de maneira tão aderente a visualidade da construção e da desconstrução cultural: estruturas gráfico-linguísticas que são lidas da esquerda para a direita, de cima para baixo, linha a linha, consoante o nosso costume. Derrida estava certo quanto a isso: numa biblioteca, por exemplo, a mesma lógica que organiza os livros por assunto é a que cria a seção dos "outros", isto é, dos livros que não se enquadram em nenhuma categoria. A desconstrução é, nesses termos, um modo de enxergar não apenas esse espaço estranho, mas a própria lógica que nos leva a estranhá-lo.

E na esfera do design, mais do que revelar criticamente os vazios constitutivos das regras e convenções, a desconstrução pode ser um poderoso modo de interferir, rearticular e intensificar a visualidade que instaura a cultura. Nesse sentido, a recente escultura da Fearless Girl (Fig. 2) é emblemática. No dia 8 de março (Dia Internacional da Mulher) de 2017, uma estátua de bronze de uma garotinha destemida, de 1,2 metros, com as mãos sobre a cintura foi instalada em frente ao grande símbolo de Wall Street: o monumento Charging Bull, um touro implacável que desde 1989 mantém-se em sua posição viril. A princípio, a garota sem medo era para ser apenas uma ação publicitária da State Street, uma empresa de gestão de investimentos, mas sua repercussão visual foi tamanha que, até o momento, ela permanece ali enfrentando o touro - e, por conseguinte, o seu dono. $O$ escultor Arturo Di Modica, ao ver sua obra compartilhando a atenção com a garotinha de bronze, queixou-se de que ela "altera o significado da sua arte", de modo que a empresa responsável teria "violado os seus direitos" (BARRON, 2017, s. p.).

Figura 2 - "Fearless Girl” 


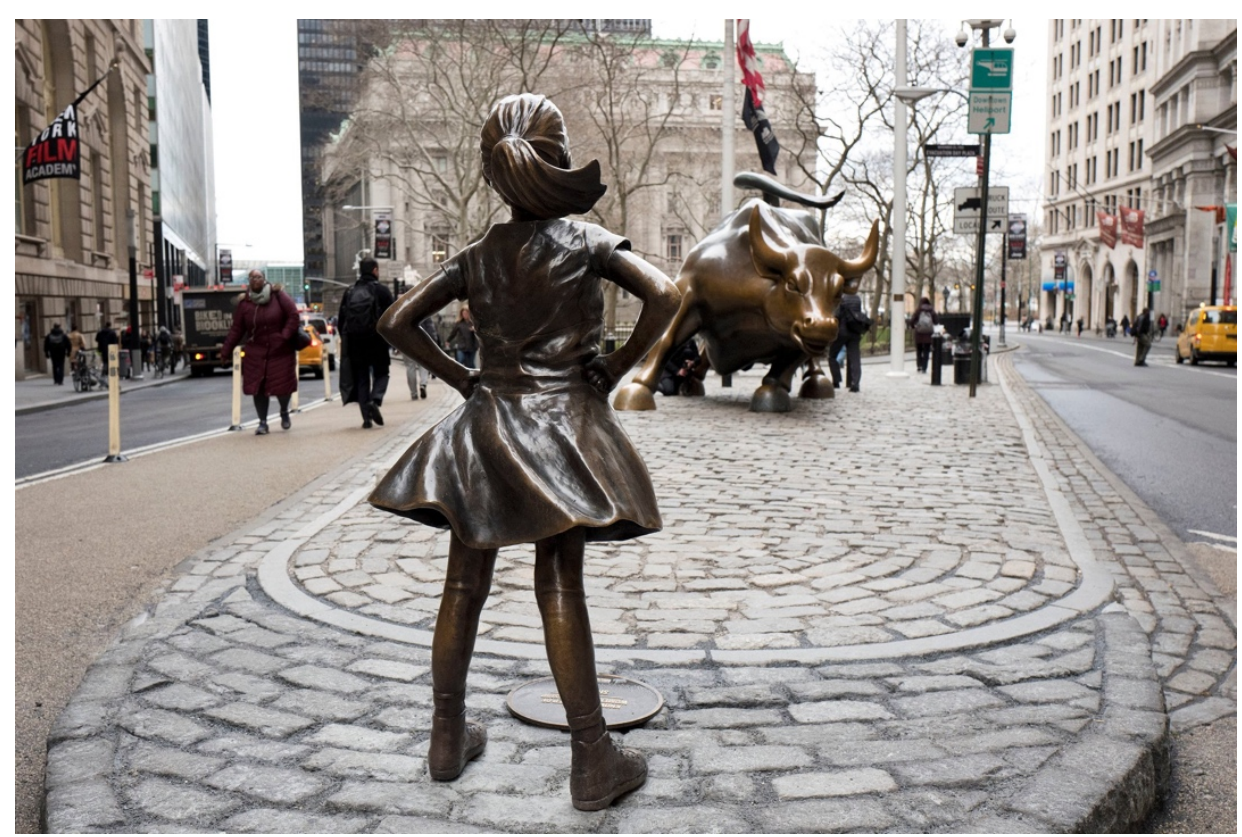

Fonte: BARRON, 2017, s. p. Créditos da fotografia: Mark Lennihan Associated Press.

Isso mostra como um signo tão facilmente compreensível como uma pequena escultura figurativa é capaz de operar uma efetiva desconstrução: o teor da Fearless Girl não é pósmoderno, pois seu intuito não é o de gerar um leque infinito de interpretações, e sim o de interferir clara e explicitamente num artefato cultural. $\mathrm{O}$ alvo não é apenas o touro capitalista, mas toda a rede de signos normativos que o circunda e cuja lacuna constitutiva sempre esteve ali, no amplo vão em frente à besta, prestes a ser habitado.

Mas a desconstrução visual, reitero, não constitui um fenômeno cultural recente; na verdade, a reescrita do mundo acompanha a própria história da escrita. $\mathrm{O}$ uso das aspas (ou "vírgula dupla", originalmente adotada em manuscritos para destacar frases importantes), por exemplo, foi ressignificado após o advento humanista da imprensa de tipos móveis: a reprodução em massa incentivava os escritores a incorporarem material de outras fontes. Com efeito, a aparente unidade formal do texto escrito será paulatinamente dissolvida, nos termos Foucault ${ }^{8}$, em um "sistema de dispersão" (2009, p. 43) - fenômeno que pode ser ilustrado por meio de uma breve comparação entre duas abordagens distintas de diagramação, ambas do século XV, apresentadas abaixo (Fig. 3).

Figura 3 - (esquerda) Página de Campanus Opera, impressa em 1445 / (direita) Página da Bíblia Latina, impressa em 1497.

\footnotetext{
8 "[...] além do título, das primeiras linhas e do ponto final, além de sua configuração interna e da forma que lhe dá autonomia, ele [o livro impresso] está preso em um sistema de remissões a outros livros, outros textos, outras frases [...] Por mais que o livro se apresente como um objeto que se tem na mão; por mais que ele se reduza ao pequeno paralelepípedo que o encerra: sua unidade é variável e relativa. Assim que a questionamos, ela perde sua evidência; não se indica a si mesma, só se constrói a partir de um campo complexo de discursos" (FOUCAULT, 2009, p. 26).
} 


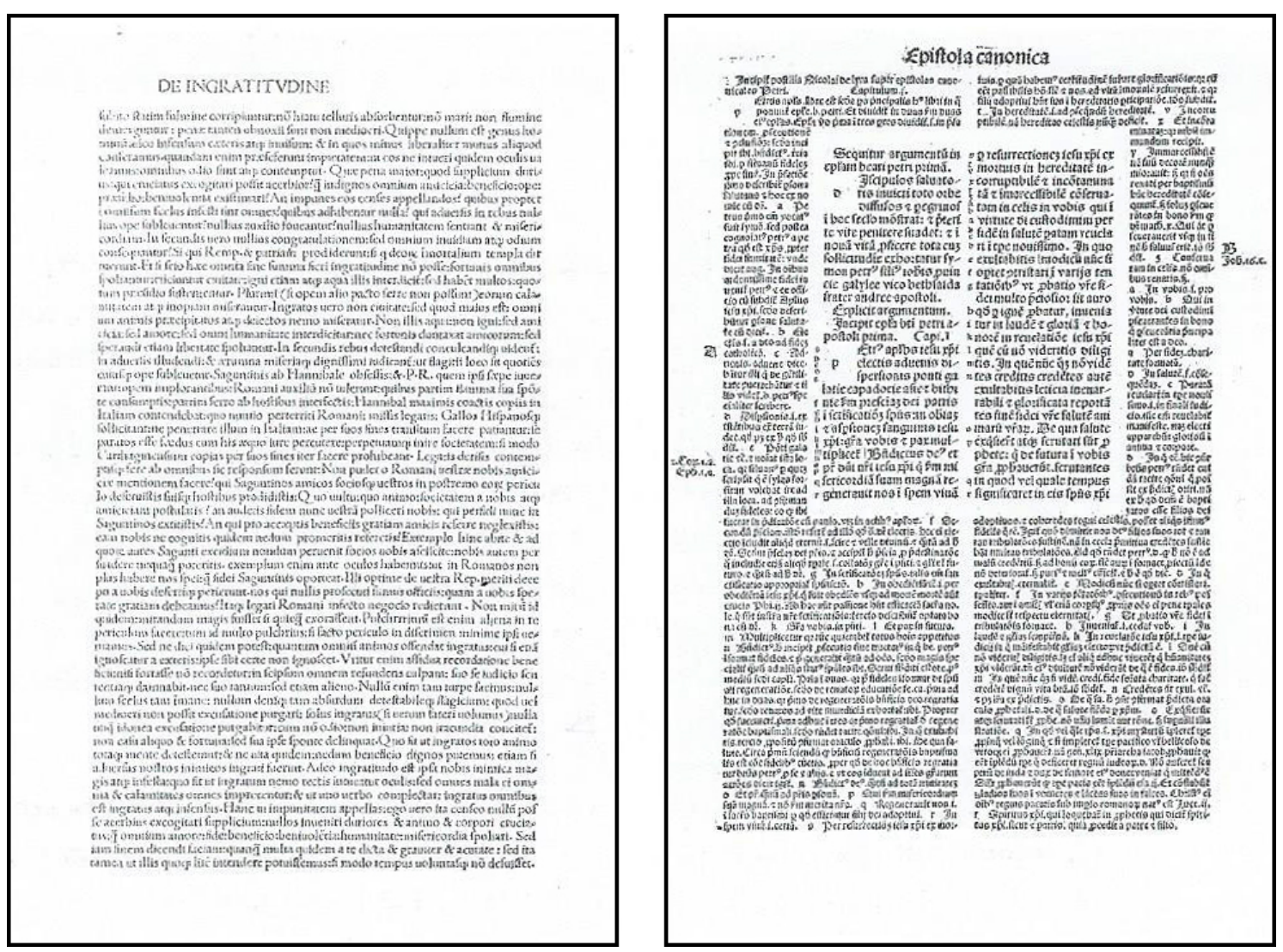

Fonte: LUPTON; MILLER, 2011, p. 16

Na página da esquerda, as margens servem como uma moldura transparente para o bloco de texto, cujo alinhamento justificado reforça seu aspecto linear e coeso. O segundo caso recorre à tradição dos comentários bíblicos, que invadem o corpo textual por meio de lacunas e diferenças gráficas. No primeiro caso, as fronteiras entre interior e exterior, bem como entre leitor e escritor, estão seguramente definidas, ao passo que no segundo caso esses limites são atenuados, tanto pelo centro quanto pelas bordas.

De modo análogo, os primeiros jornais impressos, que surgiram como meio literário de elite no século XVII, eram diagramados como se fossem livros, ou seja, pressupondo uma leitura linear, do início ao fim. Mas na medida em que, durante o século XIX, o jornal se tornava um meio popular, suas páginas assumiam dimensões maiores e incorporavam diversos elementos, como reportagens, anúncios, colunas de opinião etc. Assim o jornal impresso assume sua feição moderna, como uma colcha de retalhos que reflete a disputa de interesses editoriais, publicitários e de produção. Enquanto os primeiros jornais pareciam ser, nos termos de Lupton e Miller (2011, p. 17), "um objeto coerente e completo, a aparência do jornal popular era resultado de acordos comerciais apressados e de condições arbitrárias".

Esse modo de justaposição gráfica e conceitual motivou Derrida (1986) a tomar a tipografia como um meio privilegiado pelo qual a escrita invade o pensamento e a fala. Foi sob tal premissa que o filósofo elaborou o livro Glas (Fig. 4), com design de Richard Eckersley, que lança mão de layouts fora dos padrões acadêmicos para compilar um conjunto de textos aparelhados de maneira dispersa (com diagramação e fontes distintas), indicando assim vozes e modos de escrita heterogêneos. Glas constitui uma experimentação gráfica que incorpora, como estratégia 
deliberada de escrita, tanto as glosas dos manuscritos medievais quanto o layout caótico dos jornais modernos.

Figura 4 - Páginas do livro Glas

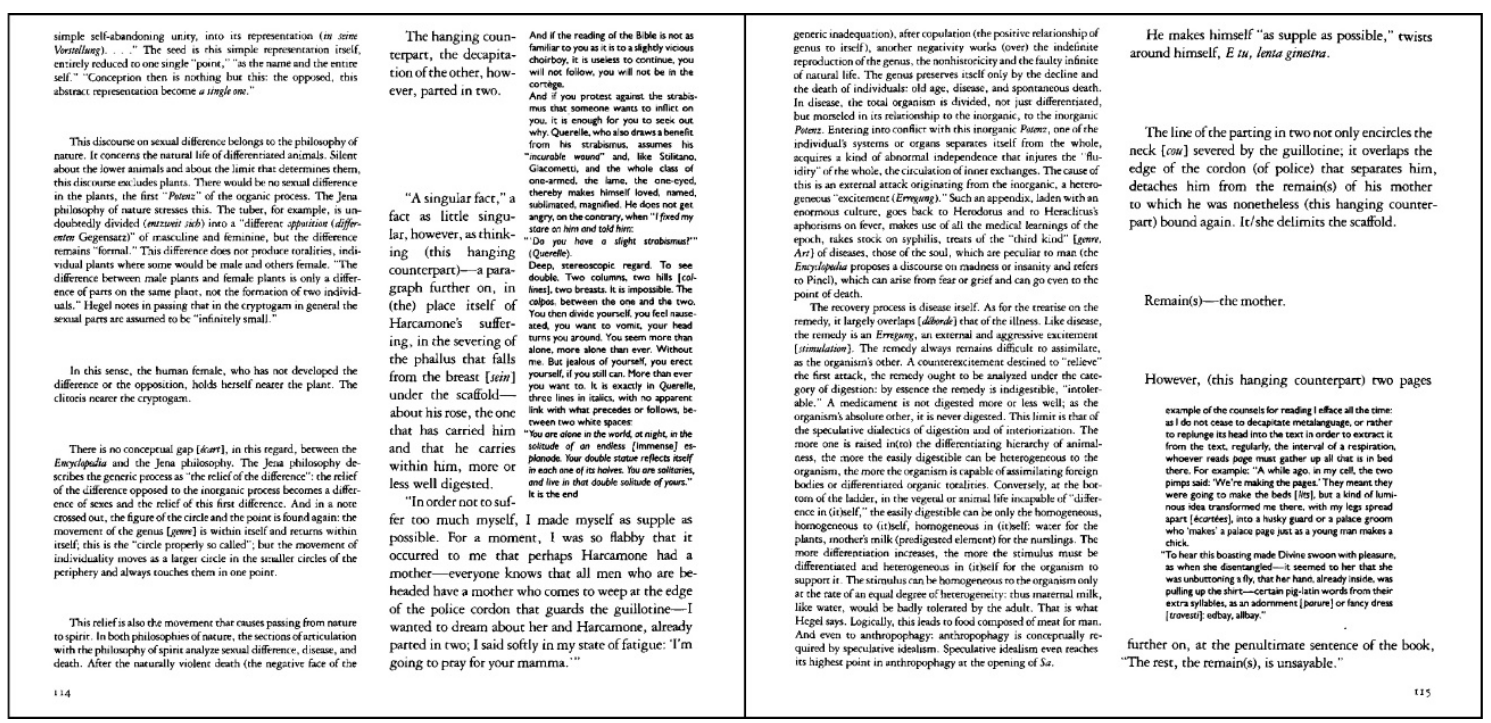

Fonte: DERRIDA, 1986, p. 114-115.

Claro está que o livro e a tipografia respondem historicamente a mudanças na filosofia, na tecnologia e nos usos da escrita. Em Modern Typography, Robin Kinross (1992) mapeia a progressiva racionalização das formas e usos das letras ao longo de vários séculos, relacionando esse processo ao estabelecimento de estruturas formais e corpos coerentes do saber. Por sua vez, Johanna Drucker (1994) escreve, em The Visible Word, sobre o lado experimental e transgressor (em oposição ao racional) da tipografia moderna.

O que a desconstrução tende a evidenciar no design gráfico é o modo como margens, alinhamentos, estilos e marcas textuais não apenas exploram a fronteira entre o interior e o exterior do corpo textual, mas o consolidam propriamente. Os signos linguísticos não existem fora dessa superfície tipográfica, cuja dispersão interna e absorção de elementos externos caracterizam toda forma de expressão humana - inclusive a manifestação aparentemente espontânea da fala, bem como as lentes supostamente "translúcidas" da câmera fotográfica.

A desconstrução, portanto, revela e explora a ubiquidade dos significados, como um processo ativo de interpretação/interpelação cultural que se recusa a colocar-se fora ou acima do ambiente cotidiano. É justamente por não se afastar das contendas culturais, do mais alto modernismo ao mais baixo kitsch, que a desconstrução reinventa o mundo - é porque ela "mente", como o dizia Platão sobre os poetas, que ela reembaralha todo tipo de verdade.

Com isso em vista, o designer gráfico pode rearticular as mecânicas de representação, não no sentido de abolir ou atenuar os padrões que constituem uma gramática, mas no sentido de dar a ver esse tecido complexo em que a cultura se inscreve. A escrita é sempre uma reescrita tanto quanto a leitura é sempre uma releitura. Como um caleidoscópio tipográfico, as palavras e as estruturas do pensamento podem ser embaralhadas e reabitadas. 


\section{Referências}

BARRON, J. Wounded by 'Fearless Girl,' Creator of 'Charging Bull' Wants Her to Move (notícia de jornal). The New York Times, 12 abr. 2017, p. A18. Disponível em: <https://www.nytimes.com/2017/04/12/nyregion/charging-bull-sculpture-wall-street-fearlessgirl.html>. Acesso em 06 nov. 2017.

BARROS, J. D. Alois Riegl e a visibilidade pura: revisitando a obra de um historiador da arte de fins do século XIX. Cultura Visual (EDUFBA), n. 18, p. 61-72, dez. 2012.

BARTHES, R. O rumor da língua. São Paulo: Martins Fontes, 2004.

CARRIER, D. Rosalind Krauss and American philosophical art criticism: from formalism to beyond postmodernism. London: Greenwood Publishing Group, 2002.

CHWAST, S. Push Pin Graphic: A Quarter Century of Innovative Design and Illustration. San Francisco: Chronicle Books, 2004.

COLLINS, M.; PAPADAKIS, A. Deconstruction, Deconstructivism, and Late-Modernism. In:

Post-Modern Design. New York: Rizzoli, 1989, p. 179-195.

DERRIDA, J. Glas. Nebraska: University of Nebraska Press, 1986.

Gramatologia. São Paulo: Perspectiva, 2008.

DRUKER, J. The Visible Word: Experimental Typography and Modern Art. Chicago: University of Chicago Press, 1994.

FOUCAULT, M. A Arqueologia do Saber. Rio de Janeiro: Forense Universitária, 2009.

Ditos e escritos III: Estética - literatura e pintura, música e cinema. Rio de Janeiro: Forense Universitária, 2011.

FREITAS, A. Contra-Arte: vanguarda, conceitualismo e arte de guerrilha - 1969-1973. Tese de doutoramento em História. Curitiba: PPGHIS-UFPR, 2007.

GOPNIK, A.; VARNEDOE, K. High and Low: Modern Art and Popular Culture. New York: Distributed Art Publications Inc., 1990.

JOHNSON, P.; WIGLEY, M. Deconstructivist Architecture. New York: Museum of Modern Art, 1988.

KINROSS, R. Modern Typography: An Essay in Critical History. London: Hyphen Press, 1992.

Fellow Readers: Notes on Multiplied Language. London: Hyphen Press, 1994.

KUNDERA, M. Die Weltliteratur. In: A cortina: ensaio em sete partes. São Paulo: Companhia das Letras, 2006, p. 33-56.

LUPTON, E.; MILLER, A. Design escrita pesquisa: a escrita no design gráfico. Porto Alegre: Bookman, 2011.

McCOY, K. Cranbrook Design: The New Discourse. New York: Rizzoli, 1990.

NEURATH, O. From hieroglyphics to Isotype: a visual autobiography. Londres: Hyphen Press, 2010. 
ONG, W. Orality and Literacy: The Technologizing of the World. New York, London: Metheun, 1982.

PAGOTTO-EUZEBIO, M. S. A Filosofia, a Cidade, a Paideia: os antigos contemporâneos. Revista Páginas de Filosofia, v. 2, n. 1, p. 195-214, jan./jun. 2010.

PORTUGAL, D. B. Éticas do design: considerações preliminares sobre os valores da produção industrial em modos de pensamento iluministas e românticos. Revista Não Obstante, v. 1, n. 1, p. 5-12, jan./jul. 2017.

STEINBERG, L. Outros critérios: confrontos com a arte do século XX. São Paulo: Cosac Naify, 2008.

VENTURI, R.; SCOTT-BROWN, D.; IZENOUR, S. Aprendendo com Las Vegas. Tradução de Pedro Maia Soares. São Paulo: Cosac Naify, 2003.

WATKINSON, R. William Morris as Designer. London: Trefoil Books, 1990.

WORRINGER, W. Abstraction and Empathy: A Contribution to the Psychology of Style. Eastford, CT: Martino Fine Books, 2014. 